\title{
Isolated limb perfusion in sarcoma: experience with melphalan as single chemotherapeutic agent at the National Cancer Institute of Colombia
}

\author{
Carlos Alfonso Duarte ${ }^{1, *}$, Andrés Felipe Rojas², Javier Ánge/ ${ }^{3}$, Sandra Díaz ${ }^{3}$, Óscar García ${ }^{3}$ \\ Mauricio García ${ }^{3}$, Carlos Lehman ${ }^{3}$ and Ricardo Sánchez ${ }^{4}$
}

${ }^{1}$ Surgical Oncology Group coordinator; ${ }^{2}$ Surgical Oncology Group fellow; ${ }^{3}$ Breast and Soft Tissue Group; ${ }^{4}$ Clinical Research Group. Instituto Nacional de Cancerología, Bogotá, Colombia

\begin{abstract}
Objective: Describe the experience in implementing the technique of isolated limb perfusion with the use of melphalan in patients with soft tissue sarcoma (STS), between 2007 and 2012. Methodology: A case series of patients diagnosed with STS and standing tumors and/or cutaneous annex carried by isolated limb perfusion Service Breast and Soft Tissues in the Instituto Nacional de Salud in Bogotá-Colombia from 2007 to 2012. Descriptive analysis of information was made. Qualitative variables were presented in frequencies and proportions and quantitative variables median and interquartile ranges (IQR) was made due to non-normal distribution. Results: They were included in the study 52 patients with a median of 53 $(I Q R=37-66)$ years, treatment response according to RECIST scale was partial in $45.83 \%$ and $39.5 \%$ progression. The definitive surgical treatment was performed in $83.3 \%$ (40). The percentage of overall saving was $45 \%$. Secondary mortality was at present in $21.57 \%$ (11) and the free disease-free survival was $50.98 \%$ (26). Conclusions: Isolated limb perfusion is a successful alternative to amputation, but in our series a low saving rate was found comparing other centers where combination therapy is used with tumor necrosis factor. It is considered advisable to carry out prospective studies with robust methodologies where this combination is used to evaluate the response rate in the Colombian population and better respond to patients with this disease.
\end{abstract}

Key words: Soft tissue sarcoma. Isolated limb perfusion. Melphalan. Therapeutic response. Mortality. Limb salvage.

Correspondence:

${ }^{*}$ C.A. Duarte

E-mail: duarte10.carlos@gmail.com
Available online: 19-12-2017 Gac Mex Oncol. 2017;16(5):260-269

www.gamo-smeo.com CC BY-NC-ND license (http://creativecommons.org/licenses/by-nc-nd/4.0/). 


\section{Introduction}

Soft tissue sarcomas (STS) comprise a heterogeneous group of mesenchymal tumors that accounts for about $1 \%$ of neoplasms worldwide 1 . These are infrequent malignancies, but they confer high burden of disease, since they occur in people who are active in terms of work. According to the 2009 statistical yearbook of the National Cancer Institute (INC - Instituto Nacional de Cancerología), in Bogotá (Colombia), there were 114 STS new cases, which represents $2.1 \%$ of total new cancer cases of this institution?

STS can occur in any anatomical region of the body, with extremities being compromised by up to $60 \%$. They occur as a progressively growing, painless mass that doesn't limit the function of the compromised limb; it is common for a delay to occur in its diagnosis, which leads to considerable growth prior to diagnosis, which in turn makes its treatment difficult, since extensive surgeries may be required, and in up to $5-10 \%$ of patients, limb amputation, with serious functional, psychological and working consequences ${ }^{3,4}$.

Treatment options are multiple. With superficial, localized $<5 \mathrm{~cm}$ lesions, the best available option is surgical resection, but it fails when the intervals of periods with new lesions are short, when lesions are numerous, large in volume or when they compromise a large proportion of the limb ${ }^{5,6}$. Combination therapies, such as neoadjuvant radiotherapy and chemotherapy, increase lesion resectability and, thereby, limb salvage. One treatment possibility that, together with these neoadjuvant therapies, has had a boom in the past few years is isolated limb perfusion (ILP). Several institutions at the global level have used the perfusion technique as a safe alternative to avoid amputation of the affected limb $b^{7,8}$. This procedure is based on a form of intra-arterial chemotherapy that consists in administering a chemotherapeutic agent at high doses, after vascular isolation of the tumor-compromised limb by means of extracorporeal circulation ${ }^{9}$. It is used for extremities compromised by malignant tumors where the indication is amputation, thus reducing systemic toxicity associated with the cytostatic agent administration'. This therapy allows reducing the lesion size and preserving the limb.

The INC is a nationwide referral center that receives an important number of patients with conditions associated with soft tissue tumors. The purpose of this study is to describe the experience with the implementation of the ILP technique between the years 2007 and 2012, and hence knowing the clinical outcomes of patients undergoing this new technique, and being able to know the results of this new therapeutic alternative for patients with unresectable tumors of the limbs in our setting.

\section{Metodology}

A case series prospective study was carried out in STS-diagnosed patients undergoing ILP at the INC Breast and Soft-Tissue Department from January 1, 2007 to December 31, 2012.

In this time period, there were 600 patients recorded with a limb sarcoma diagnosis at the Breast and Soft-Tissue Department statistical registry. Those patients with an amputation indication according to clinical and/or imaging criteria were selected, and 52 patients were included in the study. The cases were then presented in a surgical meeting with clinical oncologists, soft-tissue surgical oncologists, radiotherapists and dermatological oncologists and, after discussing each case, ILP was programmed for patients in whom it was indicated (Fig. 1). The criteria for ILP include massive compromise of a compartment involving vascular-nervous structures of the limbs, including the interosseous membrane. Follow-up of patients who underwent ILP was carried out on a weekly basis. At two months postoperatively, clinical and imaging assessment was performed in order to define the type of surgery.

Demographic data, isolated perfusion response and presenting complications were analyzed. Histopathological studies were carried out at the INC, and the report was submitted according to institutional protocols. The lesions were measured with imaging methods. The complications of patients undergoing ILP were divided in two groups: systemic and local, and were classified according to the Wieberdink scale ${ }^{10}$, which was specifically designed to evaluate isolated perfusion. Treatment response was assessed according to the RECIST 1 scale for treatment response in solid tumors ${ }^{11}$.

\section{Description of the surgical procedure}

The surgery is carried out under general anesthesia, with invasive monitoring by the Anesthesia Department, Central Venous Catheter and Arterial Line. The level of vascular exploration depends on the localization of the primary tumor. For upper limbs, possible approaches are axillary and humeral, and for upper limbs, approaches can be iliac, proximal femoral, distal femoral and popliteal. Vessels are dissected in a $5-\mathrm{cm}$ extension, 


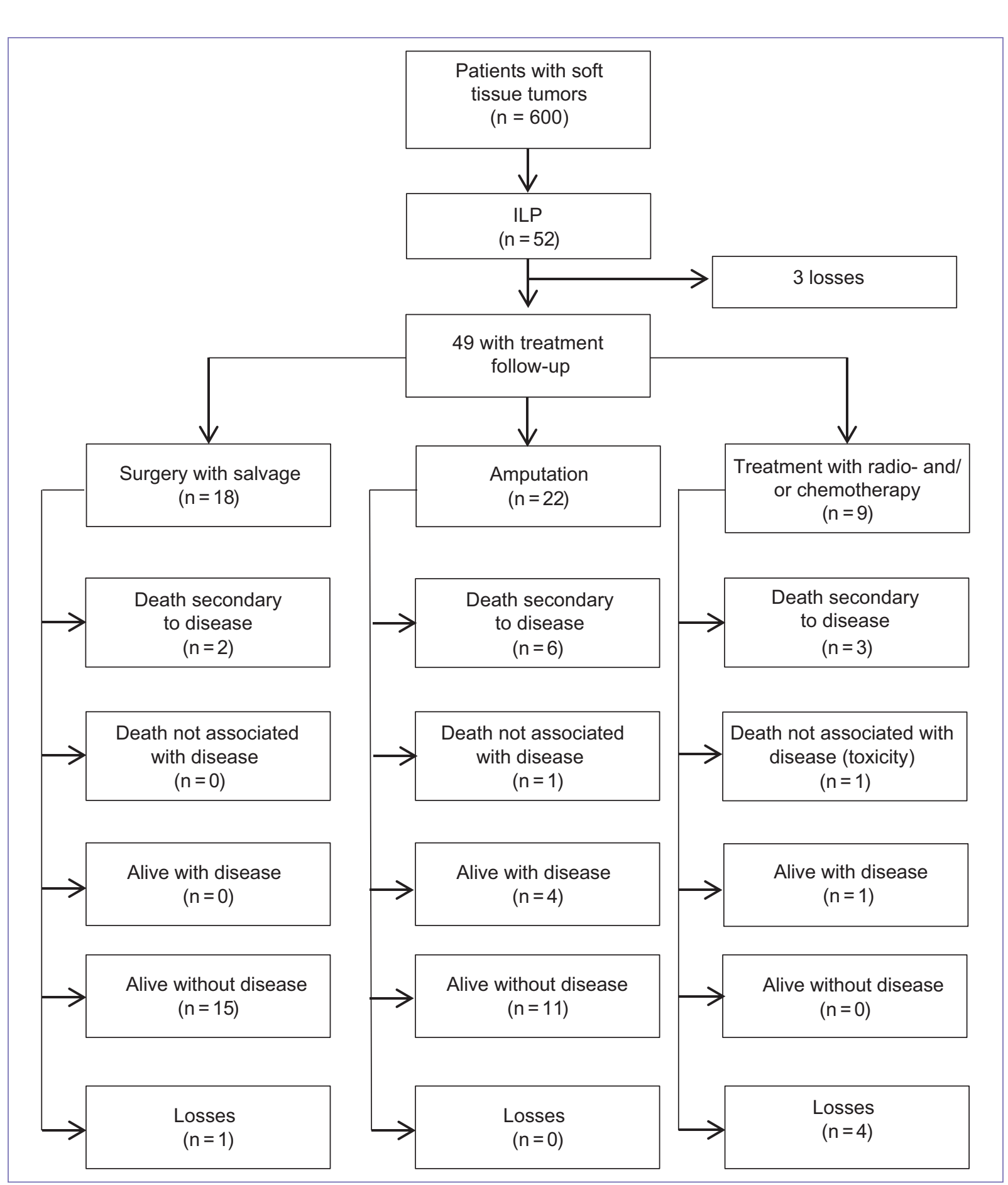

Figure 1. Cohort patients' follow-up flow chart.

with all collateral vessels being ligated. Arteriotomy and venotomy are transversely performed in order to reduce the risk of stenosis. The artery and the vein are connected by means of cannulas to a cardiopulmonary bypass circuit that includes an oxygenator and a heater; the system has to be maintained at $39{ }^{\circ} \mathrm{C}$. Limb isolation is carried out with a pneumatic tourniquet, at
$250 \mathrm{mmHg}$ pressure or, when the localization doesn't allow it, with a Rubber tourniquet.

Pyrophosphates are initially injected into the general circuit, which has the purpose to sensitize red blood cells to the technetium 99 that will be subsequently infused. With a portable gamma probe placed in the precordial region, the presence of leakage to the 
general circulation is ruled out. Next, melphalan is administered at a dose of $10 \mathrm{mg} / \mathrm{L}$ of perfused limb for lower limb lesions, and $13 \mathrm{mg} / \mathrm{L}$ for upper limbs. Perfusion is carried out for $60 \mathrm{~min}$. Then, the system is washed in order to eliminate the medication. The cannulas are removed and the artery and vein are sutured. Finally, the patient is brought to the Intensive Care Unit for monitoring (Fig. 2).

\section{Ethical considerations}

This study was approved by the INC Ethics Committee and adhered to 1993 Resolution 008430 of the Ministry of Health of Colombia, by means of which the standards of research in human subjects are regulated in Colombia. The investigators observed the principles for research in humans set forth in the Declaration of Helsinki.

\section{Statistical analysis}

Data were collected using the Excel software, 2010 version $^{\circledR}$, and were extrapolated for statistical analysis to the Stata $V 10^{\circledR}$ software. Descriptive analysis of the information was carried out, with qualitative variables being presented as frequencies and proportions and, quantitative variables, as the median and interquartile range (IQR), according to the results of the Shapiro-WiIk test.

\section{Results}

Fifty-two patients were included in the study, the demographic and clinical characteristics of whom are summarized in table 1. The participants had a median age of 53 years $(I Q R=37-66)$ at the moment the ILP was performed, with a minimum of 10 and a maximum of 81 years, and a median time of evolution of 8 months (IQR $=6-12)$, with a minimum of 1 and maximum of 60 months. A total of $51.92 \%$ of patients (27) belonged to the female gender. All patients referred symptoms of a mass, and $55-57 \%$ referred pain in the affected extremity (Fig 3). The most common subtype in the histopathological analysis was synovial sarcoma in $28.85 \%$ of patients (15), followed by undifferentiated pleomorphic sarcoma in $23.08 \%$ (12 patients), all of them high-grade. Most common localizations were left extremities $(51.92 \%)$ and the thigh $(32.69 \%)$. Caudal size of the mass was reported to range from 15 to $300 \mathrm{~mm}$, with a median of $113 \mathrm{~mm}(\mathrm{IQR}=60-154)$; anteroposterior size was reported range from 10 to $250 \mathrm{~mm}$, with a median of $80(I Q R=50-117) \mathrm{mm}$; medial size was

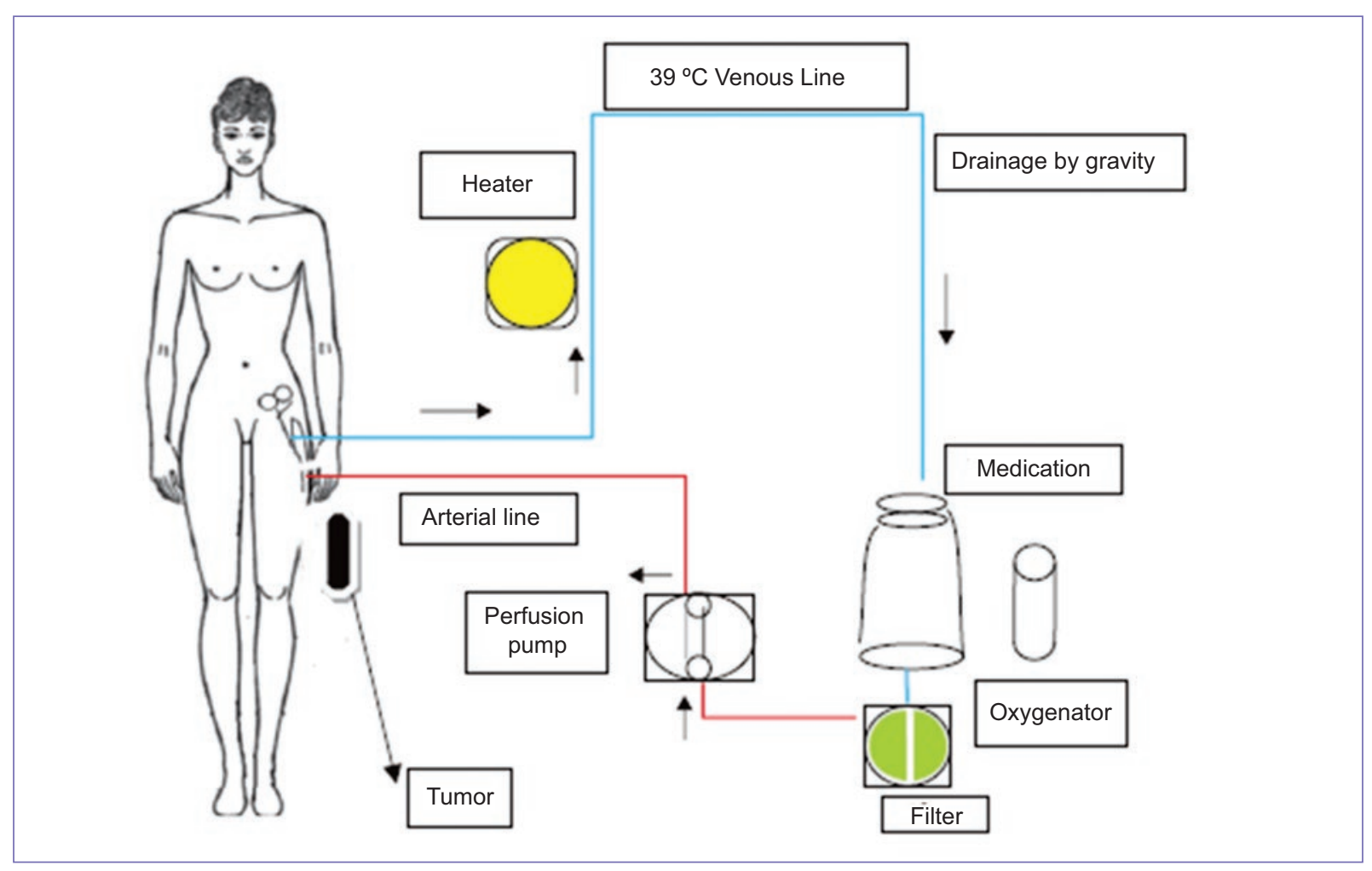

Figure 2. Scheme of the perfusion process ${ }^{20}$. 
Table 1. Demographic and clinical characteristics

\begin{tabular}{|c|c|c|c|}
\hline Clinical variables & Classification & $\mathbf{n}$ & $\%$ \\
\hline Gender $(n=52)$ & $\begin{array}{l}\text { Male } \\
\text { Female }\end{array}$ & $\begin{array}{l}25 \\
27\end{array}$ & $\begin{array}{l}48.08 \\
51.92\end{array}$ \\
\hline Type of sarcoma $(n=52)$ & $\begin{array}{l}\text { Synovial } \\
\text { Undifferentiated pleomorphic } \\
\text { Liposarcoma } \\
\text { Neural sheath } \\
\text { Leiomyosarcoma } \\
\text { Mixofibrosarcoma } \\
\text { Rhabdomyosarcoma } \\
\text { Clear cell } \\
\text { Chondrosarcoma } \\
\text { Epithelioid } \\
\text { PNET }\end{array}$ & $\begin{array}{l}15 \\
12 \\
6 \\
6 \\
5 \\
3 \\
1 \\
1 \\
1 \\
1 \\
1\end{array}$ & $\begin{array}{l}28.85 \\
23.08 \\
11.54 \\
11.54 \\
9.62 \\
5.77 \\
1.92 \\
1.92 \\
1.92 \\
1.92 \\
1.92\end{array}$ \\
\hline Laterality $(n=52)$ & $\begin{array}{l}\text { Right } \\
\text { Left }\end{array}$ & $\begin{array}{l}25 \\
27\end{array}$ & $\begin{array}{l}48.08 \\
51.92\end{array}$ \\
\hline Localization $(n=52)$ & $\begin{array}{l}\text { Forearm } \\
\text { Arm } \\
\text { Hand } \\
\text { Thigh } \\
\text { Foot } \\
\text { Leg }\end{array}$ & $\begin{array}{c}9 \\
5 \\
2 \\
17 \\
1 \\
18\end{array}$ & $\begin{array}{c}17.31 \\
9.62 \\
3.85 \\
32.69 \\
1.92 \\
34.62\end{array}$ \\
\hline Compromise $(n=51)$ & $\begin{array}{l}\text { Distal third } \\
\text { Middle third } \\
\text { Proximal third }\end{array}$ & $\begin{array}{l}20 \\
21 \\
10\end{array}$ & $\begin{array}{l}39.22 \\
41.18 \\
19.61\end{array}$ \\
\hline Depth $(n=52)$ & $\begin{array}{l}\text { Deep } \\
\text { Superficial }\end{array}$ & $\begin{array}{c}50 \\
2\end{array}$ & $\begin{array}{l}96.15 \\
3.82\end{array}$ \\
\hline Lymph node involvement $(n=52)$ & $\begin{array}{l}\text { No } \\
\text { Yes }\end{array}$ & $\begin{array}{c}46 \\
6\end{array}$ & $\begin{array}{l}88.46 \\
11.54\end{array}$ \\
\hline Metastatic involvement $(n=52)$ & $\begin{array}{l}\text { No } \\
\text { Yes }\end{array}$ & $\begin{array}{c}46 \\
6\end{array}$ & $\begin{array}{l}88.46 \\
11.54\end{array}$ \\
\hline Site of metastasis $(n=6)$ & $\begin{array}{l}\text { Axillary lymph node } \\
\text { Axillary lymph node and neck } \\
\text { Lung }\end{array}$ & $\begin{array}{l}1 \\
1 \\
4\end{array}$ & $\begin{array}{l}1.92 \\
1.92 \\
7.69\end{array}$ \\
\hline Previous treatment $(n=52)$ & $\begin{array}{l}\text { Surgery } \\
\text { Radiotherapy } \\
\text { Chemotherapy } \\
\text { Radiotherapy and chemotherapy } \\
\text { Isolated perfusion }\end{array}$ & $\begin{array}{c}22 \\
9 \\
8 \\
3 \\
1\end{array}$ & $\begin{array}{l}42.31 \\
17.31 \\
15.38 \\
5.77 \\
1.92\end{array}$ \\
\hline
\end{tabular}

PNET: Primitive neuroectodermal tumor.

reported to range from 10 to $170 \mathrm{~mm}$, with a median of $60 \mathrm{~mm}(\mathrm{IQR}=40-83)$. Most tumors were at deep level, and $11.54 \%$ (6 cases) had metastasis, most commonly to the lung.

As for ILP characteristics, median surgical time was 210 min (IQR $=160-280)$, with a minimum time of 30 and a maximum of $450 \mathrm{~min}$, whereas the perfusion time had a median of $60 \mathrm{~min}$ (IQR $=60-60)$, with a minimum of 20 and a maximum of $80 \mathrm{~min}$. Operative failure occurred in $23.5 \%$ of patients (12), with chemotherapeutical agent leakage being the main cause.
In the postoperative period, according to the Wieberdink classification, type I toxicity was found in $80.85 \%$ of cases, early complications in $11.54 \%$ ( 6 cases) and postsurgical systemic complications in $17.29 \%$ (4 patients). Other characteristics of the ILP procedure are presented in table 2. The time between ILP and definitive treatment ranged from 0 to 13 months, with a median of 3 months (IRQ $=2-4)$.

Treatment response according to RECIST criteria was partial in $45.83 \%$ of patients (22), progressive disease in $39.5 \%$ (19), stable disease in $12.5 \%$ (6) and 


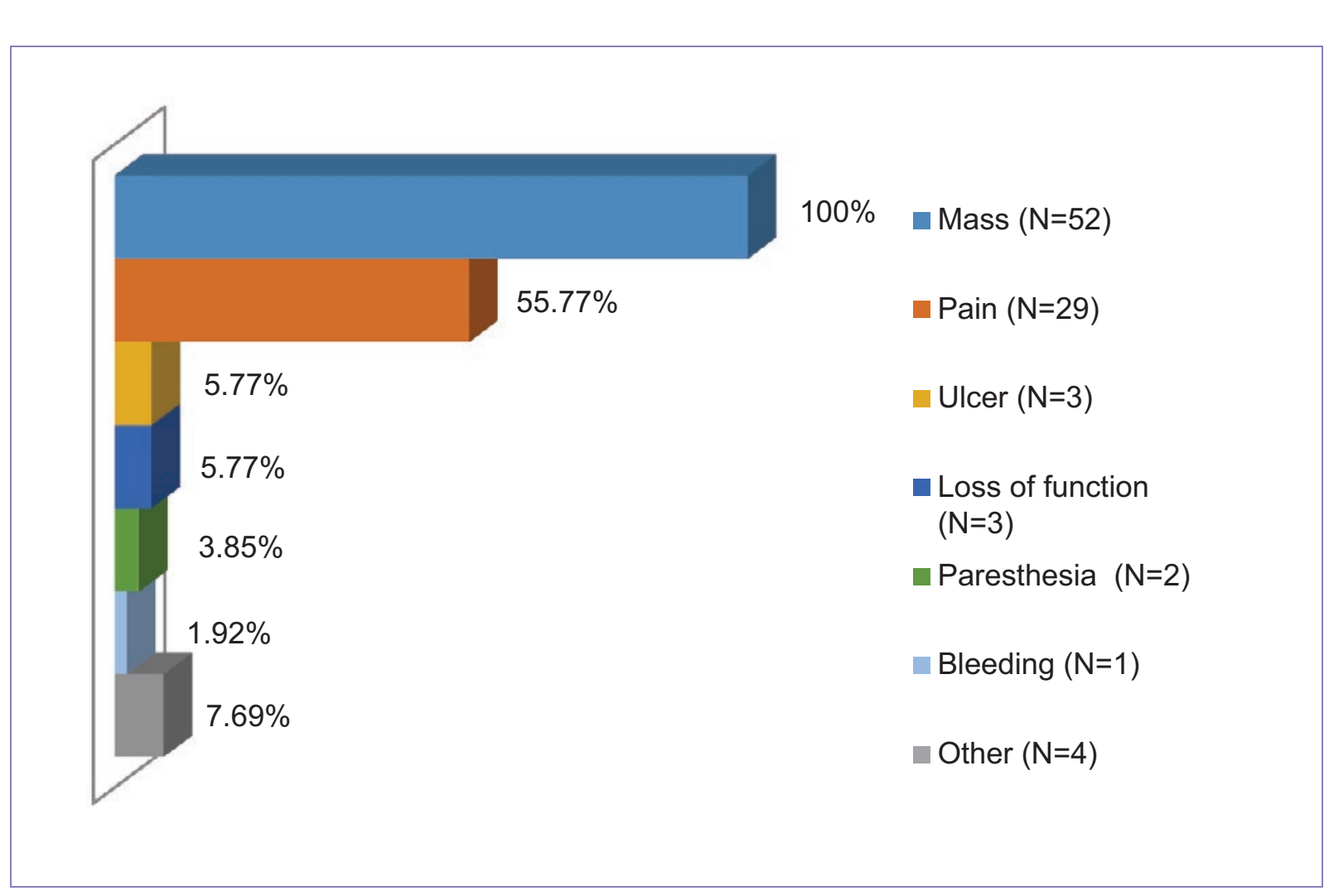

Figure 3. Percentage distribution of STS-secondary symptoms referred by patients.

complete response in $2.08 \%$ (a single patient). Definitive surgical treatment was performed in $83.3 \%$ of patients (40 in total), since two rejected surgery, two more received chemotherapy and radiotherapy, and other two received another type of treatment. Overall salvage percentage was $45 \%$ (18/40). Histopathological characteristics of resected tumors showed that $7.5 \%$ had positive margins, with a necrosis percentage $\geq 10 \%$ in $66.7 \%$ of samples. Cephalocaudal tumor size of the mass was reported to range from 5 to $480 \mathrm{~mm}$, with a median of $110 \mathrm{~mm}$ (IQR = 60-200); anteroposterior tumor size was reported to range from 5 to $440 \mathrm{~mm}$, with a median of $90 \mathrm{~mm}(\mathrm{IQR}=50-170)$; lateromedial tumor size was reported to range from 2 to $300 \mathrm{~mm}$, with a median of $60 \mathrm{~mm}(\mathrm{IQR}=30-90)$. In the group of perfused patients, $60.8 \%$ (15 patients) received initial treatments prior to the ILP with chemotherapy, $17.49 \%$ of cases ( 4 in total) did it with radiotherapy, and $17.39 \%$ (4 cases) did it with radio- and chemotherapy. In total, $98 \%$ of patients had high-grade (III) tumors.

Mortality secondary to oncologic disease was $21.57 \%$ (11 cases), whereas disease-free survival was $50.98 \%$ (26 patients). There were losses in $11.76 \%$ (6 patients) (Fig. 4), out of which three had shown partial response to the treatment, two, stable disease, and one, progressive disease.

When patients with limb salvage were compared with those who underwent amputation, salvage was found to be more common in the female gender (72.2 vs. $54.5 \%$ ), at younger age (median of 42.6 vs. 54.7 years); according to the type of sarcoma, the undifferentiated pleomorphic type was more common in those who underwent amputation (36.6\%), whereas in those with salvage, the most common was the synovial type (44.4\%). According to localization, $50 \%$ of lesions were located in the leg in those who underwent salvage surgery, while in those with amputation, $36.6 \%$ were localized in the thigh. Of the patients with amputation, $13.9 \%$ had metastatic compromise. In those with salvage surgery, median time of evolution was 8 months, and 6 in those with amputation. Mortality secondary to the disease was higher in patients with amputation (27.2 vs. $11.1 \%)$, and in those with salvage, the percentage of patients alive and free of disease was higher ( 83.3 vs. $50 \%$ ).

\section{Discussion}

ILP was described by Creech et al. in 1958, and melphalan has been the most widely used cytostatic 
Table 2. ILP procedure characteristics

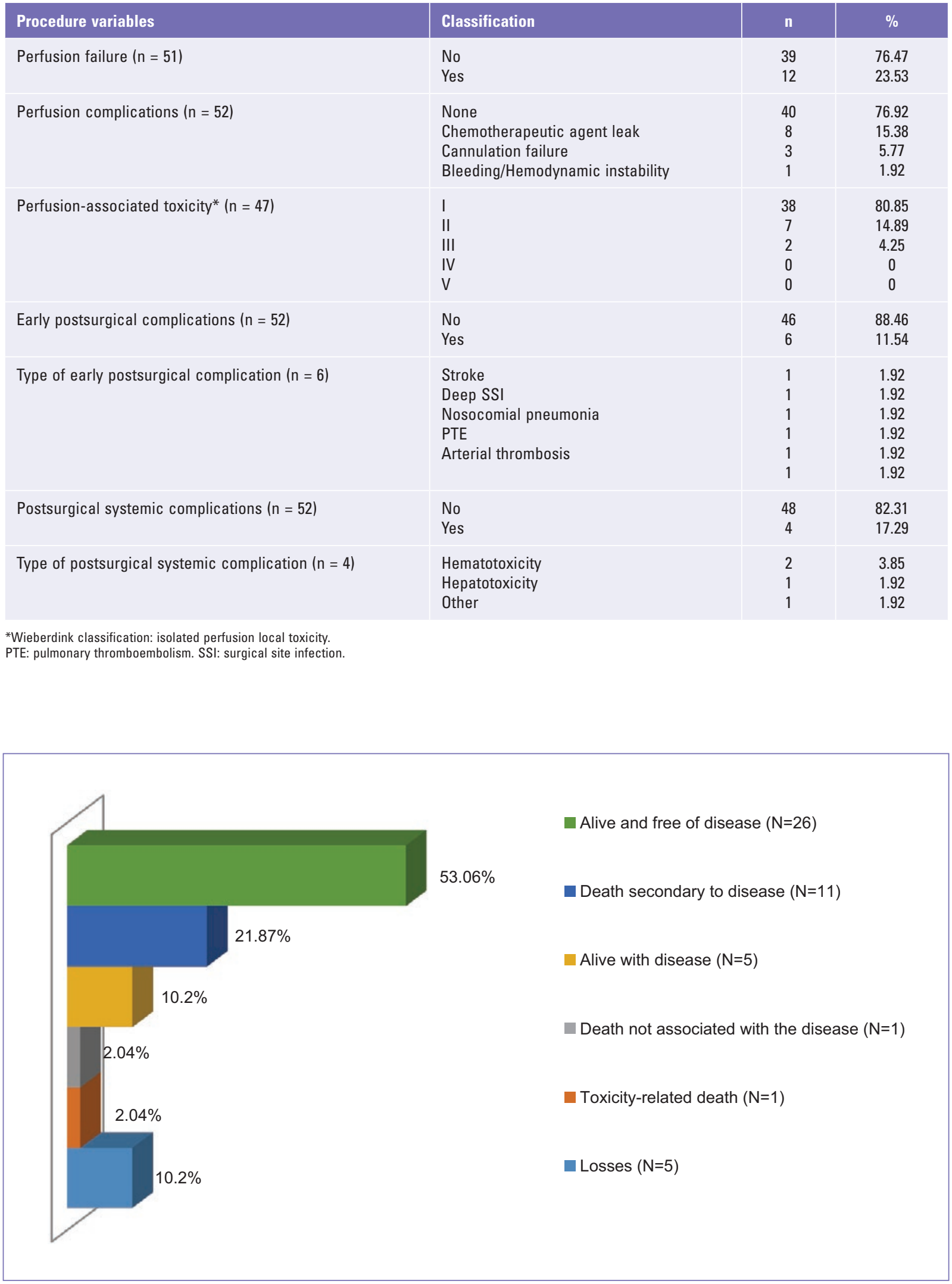

Figure 4. Surgical procedure results percentage distribution. 
drug in patients with metastatic melanoma ever since ${ }^{12}$. In contrast with the high response rates in patients with melanoma, the results in patients with STS were less encouraging ${ }^{13,14}$. The introduction of tumor necrosis factor (TNF) in ILP by Lienard et al. ${ }^{15}$ drastically improved outcomes in four patients with advanced stage limb STS, with $87 \%$ of objective responses being achieved and limb salvage in $84 \%$ of patients ${ }^{16}$.

At the INC, the ILP technique was implemented in 2007 for patients with STS and melanoma with in-transit metastasis who are not candidates to any treatment other than amputation, with the purpose to save the limb. Between 1998 and 2008, 80 major amputations were carried out in this institution by the INC Breast and Soft Tissue Department in patients diagnosed with STS and skin tumors, with $72.5 \%$ of amputations corresponding to patients with STS ${ }^{17}$. Later, between 2007 and 2008, 13 patients diagnosed with sarcomas and melanoma in-transit metastases underwent ILP, with reports of limb salvage of $76 \%$, which are similar results to those reported in the medical literature, although that study included patients with melanoma, in whom management with melphalan alone is more effective ${ }^{18,19}$.

In this new series, we managed to achieve 40 interventions, including only patients with STS, with a rate of limb salvage of $45 \%$ being obtained, which is considerably below the rates reported in other series. Several reasons why such low salvage rates occur have been identified, which include: the fact of being a fourth-level center where care is provided to cancer patients referred from multiple geographic areas of the country, with most of them corresponding to low-income or low educational level people who have limited access to appointments or have a poor health perception. Such particular conditions make for the population of cancer patients that are managed in this institution to present mainly with tumors at advanced stages ${ }^{20}$. It's important mentioning that the reason why only melphalan is used is due to TNF- $\alpha$ unavailability in Colombia.

Another reason, which is one of those with the highest weight, is that melphalan is used in our institution as the only means of antineoplastic therapy in form of perfusion, whereas in other institutions, as previously mentioned, the high rate of success is attributable to the combined use with TNF- $\alpha^{21}$. Currently, the combination of both these drugs is used in many centers as neoadjuvant treatment in ILP, with optimal responses, as shown by the systematic review conducted by Bhan$\mathrm{gu}^{22}$, which included 18 studies where the ILP result in locally-advanced STS was reported, and where the combination of melphalan and TNF- $\alpha$ was the most widely used neoadjuvant treatment. Twenty-two percent of cases achieved complete tumor response (216/964, 15 trials), with an overall response rate of $72 \%$ (660/911, 15 trials). In the median follow-up at 11 and 125 months, the rate of limb salvage was $81 \%$ in patients that otherwise would have undergone amputation.

Eggermont et al. showed convincing results of a multicenter study that included 186 patients, which led to TNF approval and registration in Europe for the treatment of sarcoma in $1999^{23}$. Eight centers participated in said study. Primary endpoints were clinical and pathologic response: $29 \%$, complete response (54 cases), $53 \%$, partial response (99), $16 \%$, stable disease (29) and $2 \%$, progressive disease (4 patients). With a median follow-up of nearly two years (22 months; range: 6-58 months), limb salvage was achieved in $82 \%$. Regional toxicity was limited, and systemic toxicity was minimal-moderate, easily managed and with no toxicity-related deaths.

Another systematic review carried out by Moreno-Ramírez et al. ${ }^{24}$ included a total of 20 studies out of 43 eligible studies, which included the analysis of 1,392 perfusions in patients with STS whose therapeutic alternative was amputation. The predominating study design was case series ( $n=15,75 \%)$, followed by cohort studies $(n=2 ; 10 \%)$, quasi-experimental studies $(n=$ $2 ; 10 \%)$, and one randomized controlled trial (5\%). Perfused chemotherapy treatment in studies on STS has mostly been the melphalan-TNF combination scheme ( $n=13$ studies; $65.00 \%$ ), with one study with melphalan alone $(5.00 \%)$ and other three with other chemotherapy combinations (15.00\%). The rate of avoided amputations as primary or secondary endpoint was analyzed in $93.75 \%$ of the selected studies. With a total of 972 perfusions analyzed for this purpose, median rate of avoided amputations was $82.00 \%$ (range: 73.00 $92.30 \%$ ). This predominance of studies with melphalan-TNF is related to a significant improvement in ILP results in STS after the introduction of TNF ${ }^{25}$.

Toxicity of the procedure was local, in $80.5 \%$ as grade I and in $14.5 \%$ as grade II. Studies where melphalan and TNF- $\alpha$ have been used have reported these grade I and II complications in between 24 and 100\% ${ }^{26-28}$. This generally implies erythema and mild edema of the limb. More serious edema and blistering on the skin, or grade III functional deterioration have been reported in $1-19 \%$ of patients, whereas, in our series, it was present in $4.2 \%$. Grades I-III occur in the ILP immediate 
postoperative period and are resolved in most patients in a couple of weeks or months after treatment. Soft tissue involvement and severe neurotoxic morbidity (grade IV) occur only in a small number of patients $(0-2 \%)$.

When patient characteristics were observed according to the outcome, we found that, in patients with limb salvage, belonging to the female gender, being younger, having the synovial histological type and smaller lesion size (median caudal size: 65 vs. $170 \mathrm{~mm}$; anteroposterior size: 52.5 vs. $115 \mathrm{~mm}$; medial size: 32.5 vs. $90 \mathrm{~mm}$ ), were more common in this patient group, as well as a better survival outcome, as it has been described in other series ${ }^{29-32}$.

Other combination that has shown encouraging results is melphalan plus actinomycin $D$, with an overall response rate of $73 \%$ (33\% complete response, $40 \%$ partial response), showing considerable rates of complications $^{33}$. On the other hand, actinomycin $\mathrm{D}$ should not be used together with TNF owing to the toxicity to normal tissues ${ }^{34}$.

ILP with chemotherapy alone is not as efficacious ad ILP with chemotherapy and TNF- $\alpha^{35}$. TNF- $\alpha$ has both an early and a late effect, which boosts melphalan selective uptake by the tumor by about 3-6-fold during the perfusion and achieves tumor vasculature selective destruction. Our results demonstrate a relatively low salvage rate with regard to that reported when melphalan and TNF are used in combination 22-24,30,36. ILP with TNF is a safe and efficacious biochemotherapeutic treatment for the management of patients with locally advanced soft tissue sarcoma of extremities; however, in the medical literature there is a deficit with regard to comparative trials showing the effectiveness of this combination. This is why it is necessary to perform studies with other methodologies that include the TNF molecule in addition to the established treatment, and that assess the type of response, the disease-free interval, overall survival and the quality of life scales for patients who receive this therapy.

\section{Conclusions}

ILP in patients with primary and recurrent irresectable soft tissue sarcomas is a successful alternative to amputation that provides limb salvage. Most patients experience some local toxicity that, generally, disappears in a few weeks or months. Amputation rate is high in comparison with other centers where TNF is additionally used as neoadjuvant therapy. It would be desirable to conduct prospective and comparative studies using this combination in order to assess the response rate in the Colombian population and this way being able to offer better responses to patients with this disease.

\section{References}

1. Ariyan CE, Brady MS. History of regional chemotherapy for cancer of the extremities. Int J Hyperthermia. 2008;24(3):185-92.

2. República de Colombia, Ministerio de la Protección Social, Instituto Nacional de Cancerología. Anuario estadístico 2009. Bogotá; 2011.

3. Eggermont AM, Brunstein F, Grunhagen D, Ten Hagen TL. Regional treatment of metastasis: role of regional perfusion. State of the art isolated limb perfusion for limb salvage. Ann Oncol. 2004;15(Suppl 4):107-12.

4. Hoekstra HJ, Van Ginkel RJ. Hyperthermic isolated limb perfusion in the management of extremity sarcoma. Curr Opin Oncol. 2003; 15(4):300-3.

5. Fraker DL. Management of in-transit melanoma of the extremity with isolated limb perfusion. Curr Treat Options Oncol. 2004; 5(3):173-84

6. Sanki A, Kroon HM, Kam PCA, Thompson JF. Isolated limb perfusion and isolated limb infusion for malignant lesions of the extremities. Curr Probl Surg. 2011;48(6):371-430.

7. Grünhagen DJ, de Wilt JHW, ten Hagen TLM, Eggermont AMM. Technology insight: utility of TNF-囚-based isolated limb perfusion to avoid amputation of irresectable tumors of the extremities. Nat Clin Pract Oncol. 2006;3(2):94-103.

8. Seinen JM, Hoekstra HJ. Isolated limb perfusion of soft tissue sarcomas: A comprehensive review of literature. Cancer Treat Rev. 2013;39(6):569-77.

9. Kettelhack $\mathrm{CH}$, Kraus TH, Hupp TH, Manner M, Schlag P. Hyperthermic limb perfusion for malignant melanoma and soft tissue sarcoma. Eur $\mathrm{J}$ Surg Oncol. 1990;16(4):370-5.

10. Wieberdink J, Benckhuysen C, Braat RP, Van Slooten EA, Olthuis GAA Dosimetry in isolation perfusion of the limbs by assessment of perfused tissue volume and grading of toxic tissue reactions. Eur $\mathrm{J}$ Cancer Clin Oncol. 1982;18(10):905-10.

11. Eisenhauer EA, Therasse $P$, Bogaerts $J$, et al. New response evaluation criteria in solid tumours: revised RECIST guideline (version 1.1). Eur $J$ Cancer. 2009;45(2):228-47.

12. Creech Jr O, Krementz ET, Ryan RF, Winblad JN. Chemotherapy of cancer: regional perfusion utilizing an extracorporeal circuit. Ann Surg. 1958;148(4):616.

13. Krementz ET, Carter RD, Sutherland CM, Hutton I. Chemotherapy of sarcomas of the limbs by regional perfusion. Ann Surg. 1977; 185(5):555.

14. Hoekstra HJ, Schraffordt Koops H, Molenaar WM, Oldhoff J. Results of isolated regional perfusion in the treatment of malignant soft tissue tumors of the extremities. Cancer. 1987;60(8):1703-7.

15. Liénard D, Ewalenko P, Delmotte JJ, Renard N, Lejeune FJ. High-dose recombinant tumor necrosis factor alpha in combination with interferon gamma and melphalan in isolation perfusion of the limbs for melanoma and sarcoma. J Clin Oncol. 1992;10(1):52-60.

16. Eggermont AM, Koops HS, Liénard D, et al. Isolated limb perfusion with high-dose tumor necrosis factor-alpha in combination with interferon-gamma and melphalan for nonresectable extremity soft tissue sarcomas: a multicenter trial. J Clin Oncol. 1996;14(10):2653-65.

17. Díaz S, Lehmann C, Villamizar L, Ángel J, Osorio D, Sánchez A. Amputaciones mayores en cirugía oncológica. Análisis retrospectivo de 80 casos en el Instituto Nacional de Cancerología. Revista Colombiana de Cancerología. 2013;17(1):3-10.

18. Liénard D, Eggermont AM, Kroon BBR, Koops HS, Lejeune FJ. Isolated limb perfusion in primary and recurrent melanoma: indications and results. Semi Surg Oncol. 1998;14(3):202-9.

19. Krementz ET, Creech Jr O, Ryan RF, Reemtsma K. An appraisal of cancer chemotherapy by regional perfusion. Ann Surg. 1962;156(3):417.

20. Duarte C, García M, Lehmann C, Sánchez R, Manrique J. Perfusión aislada de extremidades. Experiencia inicial del Instituto Nacional de Cancerología, 2007-2008. Revista Colombiana de Cancerología. 2011;15(2):67-74.

21. Grünhagen DJ, de Wilt JHW, van Geel AN, Eggermont AMM. Isolated limb perfusion for melanoma patients--a review of its indications and the role of tumour necrosis factor- $邓$. Eur J Surg Oncol. 2006;32(4):371-80.

22. Bhangu A, Broom L, Nepogodiev D, Gourevitch D, Desai A. Outcomes of isolated limb perfusion in the treatment of extremity soft tissue sarcoma: a systematic review. Eur J Surg Oncol. 2013;39(4):311-9.

23. Eggermont AM, Koops HS, Klausner JM, et al. Isolated limb perfusion with tumor necrosis factor and melphalan for limb salvage in 186 patients with locally advanced soft tissue extremity sarcomas. The cumulative multicenter European experience. Ann Surg. 1996;224(6):756. 
24. Moreno-Ramírez D, de la Cruz L, Ferrándiz L, Villegas-Portero R. Perfusión del miembro aislado en el tratamiento del melanoma y sarcoma de partes blandas. Informe técnico de evaluación Agencia de Evaluación de Tecnologías Sanitarias; 2008.

25. Bonvalot S, Rimareix F, Causeret S, et al. Hyperthermic isolated limb perfusion in locally advanced soft tissue sarcoma and progressive desmoid-type fibromatosis with TNF $1 \mathrm{mg}$ and melphalan (T1-M HILP) is safe and efficient. Ann Surg Oncol. 2009;16(12):3350-7.

26. Lasithiotakis K, Economou G, Gogas $\mathrm{H}$, et al. Hyperthermic isolated limb perfusion for recurrent melanomas and soft tissue sarcomas: feasibility and reproducibility in a multi-institutional Hellenic collaborative study. Oncol Rep. 2010;23(4):1077-83.

27. Wray CJ, Benjamin RS, Hunt KK, Cormier JN, Ross MI, Feig BW. Isolated limb perfusion for unresectable extremity sarcoma. Cancer. 2011; 117(14):3235-41.

28. Hayes AJ, Neuhaus SJ, Clark MA, Thomas JM. Isolated limb perfusion with melphalan and tumor necrosis factor $\alpha$ for advanced melanoma and soft-tissue sarcoma. Ann Surg Oncol. 2007;14(1):230-8.

29. Schwindenhammer B, Podleska LE, Kutritz A, et al. The pathologic response of resected synovial sarcomas to hyperthermic isolated limb perfusion with melphalan and TNF- $\alpha$ : a comparison with the whole group of resected soft tissue sarcomas. World J Surg Oncol. 2013; $11(1): 185$.
30. Noorda EM, Vrouenraets BC, Nieweg OE, Van Geel AN, Eggermont AMM, Kroon BBR. Repeat isolated limb perfusion with TNF区 and melphalan for recurrent limb melanoma after failure of previous perfusion. Eur J Surg Oncol. 2006;32(3):318-24.

31. Steinman J, Ariyan C, Rafferty B, Brady MS. Factors associated with response, survival, and limb salvage in patients undergoing isolated limb infusion. J Surg Oncol. 2014;109(5):405-9.

32. Eroglu A, Kocaoglu H, Demirci $S$, Akgül H. Isolated limb perfusion with cisplatin and doxorubicin for locally advanced soft tissue sarcoma of an extremity. Eur J Surg Oncol. 2000;26(3):213-21.

33. Kroon HM, Huismans AM, Kam PCA Thompson JF Isolated limb infusion with melphalan and actinomycin $D$ for melanoma: a systematic review. J Surg Oncol. 2014;109(4):348-51.

34. Seynhaeve ALB, de Wilt JHW, van Tiel SA, Eggermont AMM, ten Hagen TLM Combination of Actinomycin D with TNF-a in Isolated Limb Perfusion results in improved tumour response in soft tissue sarcoma-bearing rats but is accompanied by severe dose limiting local toxicity. Br J Cancer. 2002;86:1174-9.

35. Verhoef C, de Wilt JHW, Grünhagen DJ, van Geel AN, ten Hagen TLM, Eggermont AMM. Isolated limb perfusion with melphalan and TNF- $\alpha$ in the treatment of extremity sarcoma. Curr Treat Options Oncol. 2007;8(6):417-27.

36. Jakob J, Tunn PU, Hayes AJ, Pilz LR, Nowak K, Hohenberger P. Oncological outcome of primary non『metastatic soft tissue sarcoma treated by neoadjuvant isolated limb perfusion and tumor resection. J Surg Oncol. 2014;109(8):786-90. 